A.G. Mamalis and Yu.V. Romashov

\title{
Enhanced operability of nuclear fuel rod cylindrical cladding made with thin protective
} nanoengineered coatings

\begin{abstract}
Thin coatings made from zirconium-based alloys can increase operability of nuclear fuel cladding but thermal strain between coating and cladding can adversely affect performance. A mathematical model of thin coatings of cylindrical cladding is presented in the form of special boundary conditions for the equations of the theory of elasticity, defining the stress-strain state of the cladding. It is shown that thin coatings can noticeably decrease stresses in cladding made from zirconium-based alloys, widely used in nuclear reactors.
\end{abstract}

Keywords: accident, elasticity, thermal strain

Nanotechnology Perceptions 17 (2021) 74-81

doi: 10.4024/N01MA21A.ntp.17.01 